\title{
7B7: a novel antibody directed against the Ku70/Ku80 heterodimer blocks invasion in pancreatic and lung cancer cells
}

\author{
Dermot O'Sullivan • Michael Henry • Helena Joyce • Naomi Walsh • \\ Edel Mc Auley • Paul Dowling • Niall Swan • Michael Moriarty • \\ Paul Barnham • Martin Clynes • Annemarie Larkin
}

Received: 28 January 2014 / Accepted: 17 March 2014 /Published online: 18 April 2014

(C) International Society of Oncology and BioMarkers (ISOBM) 2014

\begin{abstract}
Development of more effective therapeutic strategies for cancers of high unmet need requires the continued discovery of disease-specific protein targets for therapeutic antibody targeting. In order to identify novel proteins associated with cancer cell invasion/metastasis, we present here an alternative to antibody targeting of cell surface proteins with an established role in invasion; our functional antibody screening approach involves the isolation and selection of MAbs that are primarily screened for their ability to inhibit tumour invasion. A clonal population of the Mia $\mathrm{PaCa}-2$, a pancreatic ductal adenocarcinoma (PDAC) cell line, which
\end{abstract}

Dermot O'Sullivan and Michael Henry contributed equally to this study.

Electronic supplementary material The online version of this article (doi:10.1007/s13277-014-1857-5) contains supplementary material, which is available to authorized users.

D. O'Sullivan • M. Henry • H. Joyce • N. Walsh • E. M. Auley • P. Dowling $\cdot$ M. Moriarty $\cdot$ M. Clynes $\cdot$ A. Larkin $(\varangle)$

National Institute for Cellular Biotechnology (NICB), Dublin City

University, Glasnevin, Dublin 9, Ireland

e-mail: annemarie.larkin@dcu.ie

H. Joyce

Molecular Therapeutics Cancer Ireland (MTCI), National Institute for Cellular Biotechnology (NICB), Dublin City University,

Glasnevin, Dublin 9, Ireland

\section{N. Swan}

National Surgical Centre for Pancreatic Cancer, St Vincent's

University Hospital, Elm Park, Dublin, Ireland

\section{P. Barnham}

Dublin City University, Biounite, Room JGO7,

R \& D Building, Glasnevin, Dublin 9, Ireland

Present Address:

D. O'Sullivan

Biomedical Diagnostics Institute,

Dublin City University, Dublin 9, Ireland displays a highly invasive phenotype, was used to generate MAbs with the objective of identifying membrane targets directly involved in cancer invasion. Selected MAb 7B7 can significantly reduce invasion in a dose-responsive manner in Mia PaCa-2 clone 3 and DLKP-M squamous lung carcinoma cells. Using immunoprecipitation and liquid chromatographytandem mass spectrometry (LC-MS-MS) analysis, the target antigen of anti-invasive antibody, 7B7, was determined to be the heterodimeric $\mathrm{Ku}$ antigen, $\mathrm{Ku} 70 / 80$, a core protein composed of the Ku70 and Ku80 subunits which is involved in non-homologous end-joining (NHEJ) DNA repair. RNA interference-mediated knockdown of Ku70 and Ku80 resulted in a marked decrease in the invasive capacity of $\mathrm{Mia} \mathrm{PaCa}-2$ clone 3 and DLKP-M cells, indicating that $\mathrm{Ku} 70 / \mathrm{Ku} 80$ is functionally involved in pancreatic and lung cancer invasion. Immunohistochemical analysis demonstrated Ku70/Ku80 immunoreactivity in 37 PDAC tumours, indicating that this heterodimer is highly expressed in this aggressive cancer type. This study demonstrates that a functional MAb screening approach coupled with immunoprecipitation/proteomic analyses can be successfully applied to identify functional antiinvasive MAbs and potential novel targets for therapeutic antibody targeting.

Keywords Monoclonal antibody · Cancer metastasis · Cancer invasion $\cdot \mathrm{Ku} 70 / \mathrm{Ku} 80 \cdot$ Target discovery

\section{Introduction}

Metastasis remains the major driver of mortality in patients with cancer, and, in contrast to primary cancer, metastasis is a major therapeutic challenge; currently, there are no effective treatments for the vast majority of metastatic cancers. Only a very small number of therapeutic targets have been investigated/evaluated clinically for their ability to limit 
metastasis — none of these are in clinical use [1, 2]. Identification of targets with a role in cancer invasion/metastasis may have the potential to be developed as novel treatment strategies to treat (or delay) metastasis. Monoclonal-antibody-based treatment of cancer has, in the last two decades, become established as one of the most successful therapeutic strategies for treating patients with haematological and solid tumours [3]. Antibody cancer therapeutics are highly specific and potent drugs, which exert their therapeutic effect through modulation of key signalling pathways to reduce cell growth or induce apoptosis and/or triggering of antibody-unique effect or functions. There are now 14 antibody-based products approved to treat cancer patients in the European Union (EU) and the USA [4, 5]. Therapeutic cancer antibodies are, however, focused on a relatively narrow set of targets; one third of all antibodies (approved and in development) are specific for just five targets [5, 6]. Currently, the key challenge in new antibody cancer therapeutics is the continued discovery of novel targets that are associated with hallmarks of cancer pathophysiology such as metastatic potential and drug sensitivity that are suitable for antibody-based targeting. The ideal tumour target antigen will be easily accessible from the tumour neovasculature and shows abundant tumour expression with limited normal tissue expression.

First generation antibodies such as trastuzumab and rituximab show significant clinical benefits and have revolutionised treatment of human epidermal growth factor receptor 2 (HER-2) positive breast cancer and CD-20 positive lymphomas. However, conventional unmodified antibodies have limitations such as low tumour to blood ratio due to long serum half-life, limited tissue penetration and specificity for a single epitope, and they can sometimes be limited in efficacy [4]. There has been a drive to improve established targeted therapeutic antibodies using glycoengineering approaches to increase potency (e.g. development of non-fucosylated antibodies) and the use of antibody fragments for better tissue penetration. Development of bispecific antibodies (bsABs) (e.g. catumaxomab) and trifunctional antibodies is a big growth area; these antibodies can bind to two different tumour antigens or to a tumour antigen and an antigen in the tumour stroma/microenvironment such as an immune killer cell [7, 8]. Antibody-drug conjugates (ADCs) such as the recently approved trastuzumab-DM1 aim to overcome the limitations of non-specific cytotoxics and ineffective MAb therapy, through the use of a highly potent cytotoxic agent (payload) which is directed to the tumour by appending it to an antibody or antibody fragment. ADCs currently account for around $15 \%$ of the clinical stage anticancer-antibody-based pipeline outnumbering bispecific antibodies and antibody fragments [9]. Currently, the key challenge for ADC cancer therapeutics is the ongoing identification of tractable targets [10].

Large numbers of potential cancer-associated antigens have been identified in a number of different cancer types using various high-throughput "omics" platforms [11]. However, for the most part, these approaches did not distinguish between targets that are directly involved in the cancer pathology from those that are merely bystanders with no functional contribution to tumourogenesis. All of these candidate targets, obviously then, require extensive characterisation and validation to define their relevant functional role, if any, in cancer. It is imperative that a greater emphasis is placed upon targets that are functionally relevant to cancer development and progression. The significant contribution of phenotypic screening is well recognised in first in-class small molecule drug discovery [12]. The most commonly used approach to therapeutic antibody discovery has been to generate antibodies that are specifically directed at pre-defined, well-characterised cell surface proteins or newly described proteins that are less well characterised, with respect to cancer. Early antibody candidates are generally identified using traditional hybridoma technology developed by Kohler and Milstein or phage display platforms which are adapted easily for high-throughput antibody generation [13]. Therapeutic antibody discovery is now also starting to focus on MAb targets that are functionally relevant to the cancer disease process, with "function first" discovery or "phenotypic antibody screening" approaches being described for identification of candidate MAbs that are functionally involved in cancer tumourogenesis [14-16].

Our laboratory previously isolated isogenic populations of the PDAC cell line, Mia PaCa-2 clone 3, which displays high levels of invasion in vitro, and $\mathrm{Mia} \mathrm{PaCa}-2$ clone 8 , which is poorly invasive in vitro [17]. The use of isogenic cell lines with different phenotypes with respect to metastasis is a very useful model to aid in the identification of potential cancer targets. In this study, we have used a functional MAb screening approach (based on ability to inhibit tumour invasion in vitro) to generate functional anti-invasive MAbs using the Mia PaCa-2 clone 3 cell line as an immunogen, in order to identify potential targets with a direct role in cancer invasion. Immunoprecipitation followed by liquid chromatographytandem mass spectrometry (LC-MS-MS) analyses was used for target identification of the selected anti-invasive antibody.

\section{Materials and methods}

\section{Cell lines}

The triple-negative breast carcinoma (TNBC), MDA-MB231, HER-2 positive breast, SKBR-3, large cell lung NCIH1229 and the HCT-116 colon carcinoma cell lines were obtained from the American Tissue Culture Collection (ATCC), Rockville, MD, USA. The SNB-19 glioma cell line was obtained from the German Collection of Microorganisms and Cell Cultures. The Mia PaCa-2 clone 3 pancreatic cancer cell line and the DLKP-M squamous lung carcinoma cell line were established in our own laboratory $[17,18]$. 
Hybridoma generation

The immunogen chosen for the MAb generation was Mia PaCa-2 clone 3 , an invasive clonal variant of the pancreatic cell line Mia PaCa-2 [17]. Prior to immunisations, a nonenzymatic cell dissociation buffer was used to remove cells from flasks $\left(2 \times 10^{6}\right.$ cells $(50-\mu$ l volume) $)$ following which cells were washed and re-suspended in phosphate-buffered saline (PBS) plus an equal volume of lipopeptide adjuvant, Pam3Cys-SKKKK (EMC microcollections, Germany; L2000). Each mouse received a primary immunisation administered by an intraperitoneal injection, followed by four booster immunisations administered at three weekly intervals. Three days prior to cell fusion, mice received one final immunisation. Cell fusion of the immunised spleen B-cells with SP/2/O-Ag myeloma cells was carried out using a modification of the fusion protocol outlined by Kohler and Milstein [13]. Fused cells were plated out in 48-well plates and incubated undisturbed for 10-12 days in a humidified chamber at $37^{\circ} \mathrm{C} / 5 \% \mathrm{CO}_{2}$. Immunisations were carried out at the Royal College of Surgeons (RCSI) Biomedical Research Facility, Beaumont Hospital, Dublin 9, Ireland; all immunisation protocols were licensed by the Department of Health and Children, Ireland.

\section{Screening of hybridomas}

Hybridomas were allowed to form large colonies and grow for at least 10 days undisturbed before supernatant was removed to screen for specific antibody production. Hybridoma supernatants were screened directly for their ability to inhibit cell invasion in Mia PaCa-2 clone 3 cells and for their ability to show membrane immunoreactivity on unfixed Mia PaCa-2 clone 3 cells.

\section{Immunofluorescence studies}

Cells were suspended to a concentration of $2 \times 10^{6}$ cells $/ \mathrm{ml}$, added to 10-well 7-mm microscope slides (Thermo Fisher Scientific), and incubated overnight at $37{ }^{\circ} \mathrm{C}$. Excess supernatant was removed, and the microscope slides were rinsed gently with PBS. Hybridoma supernatants were added to each well (PBS was added to one well as a negative control). For fixed cell immunofluorescence studies, cells were fixed in icecold acetone for $2 \mathrm{~min}$, followed by air-drying for $15 \mathrm{~min}$ prior to application of antibody 7B7. All slides were incubated overnight at $4{ }^{\circ} \mathrm{C}$. Primary antibodies were removed by gently washing three times in PBS. A volume of $30 \mu \mathrm{l}$ of secondary antibody, fluorescein isothiocyanate (FITC)-linked rabbit antimouse Ig (Dako, F0261), diluted 1/40, was added to each well, followed by a 30-min incubation at room temperature. Secondary antibody was removed by gently washing three times in PBS. Each slide was mounted using VECTASHIELD mounting medium (Vector, H-100), coverslipped and viewed using a Nikon phase contrast microscope fitted with an FITC filter.

96-well invasion assays

This screening assay was adapted from the standard Boyden chamber transwell assay described previously [19], which is a modification of the method of Albini et al. [20]. Briefly, using Millipore 96-well invasion plates (Millipore, MAMIC8S10), $50 \mu$ of Matrigel (1 mg/ml) (BD Biosciences, 354234) was dispensed into each insert; the plate was incubated overnight at $4{ }^{\circ} \mathrm{C}$, followed by the removal of any excess Matrigel. Cells were harvested at a concentration of $2.5 \times 10^{4}$ cells $/ \mathrm{ml}$ in media, and $50 \mu \mathrm{l}$ was added to each insert, along with an equal volume of antibody or control hybridoma medium (no antibody). A volume of $150 \mu \mathrm{l}$ media was added to each insert well. Cells were incubated at $37^{\circ} \mathrm{C}$ for $48 \mathrm{~h}$. Following this, the inserts were washed with PBS to remove any cells, while the outside of the insert was stained with $0.25 \%$ crystal violet. Stained inserts were viewed using a Nikon inverted microscope and scored as having either decreased levels of invasion or no effect on invasion relative to control hybridoma medium inserts (no hybridoma supernatant, representing $100 \%$ invasion). Those supernatants showing a decrease in invasion were re-screened using this same method.

\section{4-well invasion assays}

For 24-well invasion assays, Costar 24-well plates (Costar, 3524), containing $8.0 \mu \mathrm{m}$ pore-sized inserts (BD Biosciences, 353097), were used. A volume of $100 \mu \mathrm{l}$ of Matrigel was dispensed into each insert, a cell suspension of $1 \times 10^{6}$ cells $/ \mathrm{ml}$ was used, and $100 \mu \mathrm{l}$ of antibody or control hybridoma medium (no antibody) was added to each insert; $500 \mu \mathrm{l}$ media were added to each insert well. Cells were incubated at $37^{\circ} \mathrm{C}$ for either 24 or $48 \mathrm{~h}$, depending on the cell line used. The total number of invading cells was determined by counting the number of cells per field in 10 random fields at $\times 200$ magnification. The average number of cells per field was then multiplied by a factor of 140 as described previously [19].

\section{Motility assays}

Motility assays were carried out in an identical manner to 24well invasion assays, as described above, with the exception that the inserts were not coated in Matrigel.

\section{Proliferation assays}

Cells were harvested at a concentration of $2 \times 10^{4}$ cells $/ \mathrm{ml}$ in media. Volumes of $100 \mu \mathrm{l} /$ well of these cell suspensions were added to a 96-well plate (Costar, 3596) using a multichannel 
pipette. Plates were gently agitated to ensure an even dispersion of cells over a given plate. Cells were incubated at $37^{\circ} \mathrm{C}$ in $5 \% \mathrm{CO}_{2}$ overnight. Following this, $100 \mu \mathrm{l}$ of antibody was added to each well. Control wells had $100 \mu$ l hybridoma media added to the cell suspension. Plates were gently agitated, as described above, and incubated at $37^{\circ} \mathrm{C}$ in $5 \% \mathrm{CO}_{2}$ for 6/7 days, until the control wells have reached 80-90\% confluency. Assessment of cell survival in the presence of the antibodies relative to control (no MAb-hybridoma control medium only) was determined by acid phosphatase assay as previously described [21].

\section{Adhesion assays}

Adhesion assays were performed as described previously [19]. A volume of $250 \mu \mathrm{l}$ of extracellular matrix (ECM) proteins was placed into each well of 24-well plates and incubated overnight at $4{ }^{\circ} \mathrm{C}$. Excess solution was removed from the wells, followed by washing two times with sterile PBS. To reduce non-specific binding, $0.5 \mathrm{ml}$ of sterile $0.1 \%$ BSA/PBS solution was dispensed into each well. The plates were incubated at $37{ }^{\circ} \mathrm{C}$ for $20 \mathrm{~min}$ and then rinsed twice again with sterile PBS. Cells were harvested and re-suspended in media at a concentration of $2.5 \times 10^{4}$ cells $/ \mathrm{ml}$. Aliquots of $1 \mathrm{ml}$ of cells were plated onto 24 -well plates, in triplicate, and incubated for $60 \mathrm{~min}$. The medium was then removed from the wells and rinsed gently with sterile PBS. The cell number attached was assessed using the acid phosphatase assay.

\section{Zymography}

DLKP-M cells were treated with MAb $7 \mathrm{~B} 7(50 \mu \mathrm{g} / \mathrm{ml})$ or control hybridoma (no MAb) for $24 \mathrm{~h}$ and subsequently transferred into serum-free medium for the collection of conditioned medium for zymographic analysis (over $72 \mathrm{~h}$ ). Conditioned medium was concentrated $20 \times$ using an Amicon Ultra Centrifugal Filter device (5 k MW cut-off) and loaded onto Novex gelatin (Invitrogen EC6175) and casein (Invitrogen EC6405) gels using a $2 \times$ non-reducing sample buffer (Novex), renatured in zymogram renaturing buffer and developed in zymogram developing buffer (Invitrogen). Gels were stained with Brilliant blue $\mathrm{G}$ Colloidal Coomassie (Sigma, B2025); zones of gelatinolytic/ casein activity were detected as clear bands against a blue background.

\section{Isotype analysis}

Isotyping of MAb 7B7 was carried out using the Isostrip Monoclonal Antibody Isotyping kit (Roche Diagnostics Gmbh, 1493027).
Immunoprecipitation

Prior to immunoprecipitation, MAb 7B7 was purified using the Pierce NAb Spin Purification Kit (Pierce, 20530) and dialyzed using a Pierce Slide-A-Lyzer MINI Dialysis Unit (Pierce, 69576). Cells were grown to 80-90 \% confluency, removed from flasks, pelleted and washed three times in PBS. Whole cell extracts were prepared by re-suspending cells in $1.5 \mathrm{ml}$ of radioimmunoprecipitation assay (RIPA) lysis buffer (Sigma, R0278), sonicating for $5 \mathrm{~min}$ and centrifuging at 14,000 rpm for 10 min at $4{ }^{\circ} \mathrm{C}$. The $7 \mathrm{~B} 7$ antigen(s) were immunoprecipitated from these samples using the Direct IP Kit from Pierce (45335), as per the manufacturer's instructions. Briefly, protein-Lpurified MAb 7B7 was covalently immobilised on aldehydeactivated agarose beads overnight at $4{ }^{\circ} \mathrm{C}$. The antigen (whole cell extracts of Mia PaCa-2 clone 3 or DLKP-M cells) was then added to immobilised antibody gel mixture together with binding buffer on a rocking platform overnight at $4{ }^{\circ} \mathrm{C}$. The antigens were eluted from the beaded agarose into the elution buffer (IgM Elution Buffer, Pierce) using microcentrifuge spin cups. Fractions were neutralised through the addition of Tris- $\mathrm{HCl}$, $\mathrm{pH}$ 8.8. Eluted fractions were prepared for gel electrophoresis using NuPAGE LDS sample buffer (Invitrogen, NP007). Following gel electrophoresis, gels were stained with Brilliant Blue Colloidal Coomassie to visualise precipitated proteins. For validation of mass spectrometry identifications, the gels were probed with relevant antibodies $(\mathrm{Ku} 70$ and $\mathrm{Ku} 80$ specific antibodies, Abcam, UK) for Western blot analysis.

\section{Protein identification using LC-MS-MS}

LC-MS/MS was performed on an UltiMate 3000 Nano-LC system (Dionex), interfaced to an LTQ Orbitrap XL (Thermo Fisher Scientific). Preparation of samples was based on the method described by Shevehenko et al. [22]. Briefly, protein bands were excised from the Coomassie-stained gel and were destained. Samples were then dehydrated and digested, and peptides were extracted with acetonitrile $/ 0.1 \%$ formic acid. A $5 \mu \mathrm{l}$ aliquot of sample was loaded onto a trapping column, and the peptides were eluted into a C18 PepMap100 nanocolumn. Peptides were then separated using mobile phase gradient. LC-MS/MS data were acquired in data-dependent acquisition (DDA) mode controlled by Xcalibur 2.0.7 software (Thermo Fisher Scientific).

\section{Bioinformatic profiling of identified proteins}

Database searches were performed using TurboSEQUEST software (Bioworks Browser version 3.3.1) (Thermo Fisher Scientific) using the human subset from the SWISS-PROT database. The following filters were applied: for charge state 1, xcorr $>1.5$; for charge state 2, xcorr $>2.5$; and for charge state $3, \mathrm{xcorr}>3.5$. 
RNA interference-mediated knockdown of Ku70 and Ku80

Two pre-designed small interfering RNAs (siRNAs, Ambion) were chosen that target $\mathrm{Ku} 70$ and $\mathrm{Ku} 80$, respectively ( $\mathrm{Ku} 70$ Ambion s14952 and s14953; Ku80-Ambion s5455 and s52594), and transiently transfected into cells. Each set of siRNA transfections carried out was accompanied with a control (non-transfected) and a scrambled (SCR) transfection (Ambion, 4390843). Solutions of siRNA at a final concentration of $30 \mathrm{~nm}$ were prepared in Opti-MEM (Invitrogen). The siRNA experiments were set up using 2- $\mu$ l NeoFX (Ambion, AM4511), to transfect $30 \mathrm{~nm}$ siRNA at a cell density of $3 \times$ $10^{5} \mathrm{ml}$ in a six-well plate. Transfection medium was removed after $24 \mathrm{~h}$ and replaced with fresh growth medium. A kinesinspecific siRNA (Ambion) was used as a positive control in all knockdown experiments to assess the efficiency of transfections. The transfected cells were collected at 72 and $96 \mathrm{~h}$ for immunoblotting and assayed for changes in invasion capacity at 24 or $48 \mathrm{~h}$ using the in vitro invasion assay, as described above.

\section{Immunoblotting}

Whole cell lysates were extracted using RIPA buffer (Sigma) containing protease inhibitor cocktail (Roche) and centrifuged for $15 \mathrm{~min}$ at $16,000 \mathrm{~g}$ at $4{ }^{\circ} \mathrm{C}$. Protein concentrations were determined using the BCA protein assay kit (Pierce) according to the manufacturer's instructions. Concentrations of 15 $30 \mu \mathrm{g}$ of protein (whole cell extracts or immunoprecipitated proteins) were separated using 4-12\% gradient gels (Invitrogen) under reducing conditions. Proteins were transferred to PVDF membranes (Roche Diagnostic $\mathrm{GmbH}$ ). The membranes were blocked for $2 \mathrm{~h}$ at room temperature with Starting Block ${ }^{\mathrm{TM}}$ Blocking Buffer (Pierce). The membranes were probed with MAb 7B7 supernatants, anti-Ku70 and antiKu80 antibodies (Abcam, UK), $\beta$-actin or $\alpha$-tubulin (T5168, A5441, Sigma). The membranes were washed three times for 5 min with $1 \times$ Tris-buffered saline (TBS)/Tween-20 $(0.5 \% \mathrm{v} /$ $v$ ) and incubated with an anti-mouse HRP-conjugated secondary antibody (Dako) for $1 \mathrm{~h}$ at room temperature and washing step repeated. Detection was performed with ECL reagents and Amersham Hyperfilm ${ }^{\mathrm{TM}}$ chemiluminescence film (GE Healthcare).

\section{Immunohistochemistry}

A commercially available pancreatic cancer tissue microarray (TMA) (PA1001, US BioMax), comprising of duplicate tissue cores from 40 pancreatic cancers (including 37 pancreatic ductal adenocarcinoma (PDAC) tumours) and 6 adjacent non-cancer tissues, was stained for $\mathrm{Ku} 70 / \mathrm{Ku} 80$ expression using an anti-Ku70/Ku80 polyclonal antibody suitable for immunohistochemistry (IHC) (Abcam, UK). Staining was performed using an automated IHC staining apparatus (Autostainer, Dako) according to the manufacturer's guidelines. Briefly, following deparaffinisation and rehydration, the slides were subjected to an antigen retrieval step consisting of 20-min incubation in pH 6.0 buffer (Target Retrieval, Dako). The slides were counterstained with haematoxylin, dehydrated in graded alcohols and glass-mounted (DPX, Sigma). Negative control (primary antibody omitted, replaced by TBS) and positive control (tonsil) slides were processed at the same time. TMA cores were scored according to the intensity of the $\mathrm{Ku} 70 / \mathrm{Ku} 80$ immunoreactivity observed (weak, moderate, and strong).

\section{Quantification of MAb 7B7}

MAb 7B7 was quantified using the mouse IgM ELISA quantification from Bethyl Laboratories, USA (E90-101).

\section{Statistical analysis}

All data are presented as mean \pm standard deviation (SD). Analysis of the difference of comparisons, scrambled control siRNA versus siRNA-treated mean invasion and motility counts, adherence absorbance, and percentage survival calculated was performed using the Student's $t$ test (two-tailed, unpaired with equal variance). A $p$ value of $\leq 0.05, \leq 0.01$, and $\leq 0.005$ was deemed statistically significant. Statistical analysis was performed using Microsoft Excel. All experiments were repeated a minimum of three times, with the exception of initial hybridoma invasion screening assays and IHC analysis of $\mathrm{Ku} 70 / \mathrm{Ku} 80$.

\section{Results}

\section{Isolation of anti-invasive MAbs}

Since trypsin may lead to the loss of cell surface antigens, a non-enzymatic cell disassociation buffer (Sigma, C5914) was used to remove cells from flasks prior to preparation of immunogen and for all screening assays for antibody characterisation studies. Following fusion, 335 hybridoma supernatants (77.5\% fusion efficiency) were screened using a 96-well Boyden chamber invasion assay platform for their ability to block invasion in Mia PaCa-2 clone 3 cells. Selected hybridoma supernatants were re-screened twice (duplicate samples) using the 96-well invasion Boyden chamber assay method. Seven supernatants, 8B3, 1E5, 7C3, 7B7, 9D6, 5B1 and 6E2, were selected on the basis of a decrease in invasion observed in relation to invasion observed on controls (hybridoma control medium). These seven hybridomas were then expanded for further characterisation. Supernatants (triplicate samples) were re-screened by both 96-well and 24-well invasion assays. 

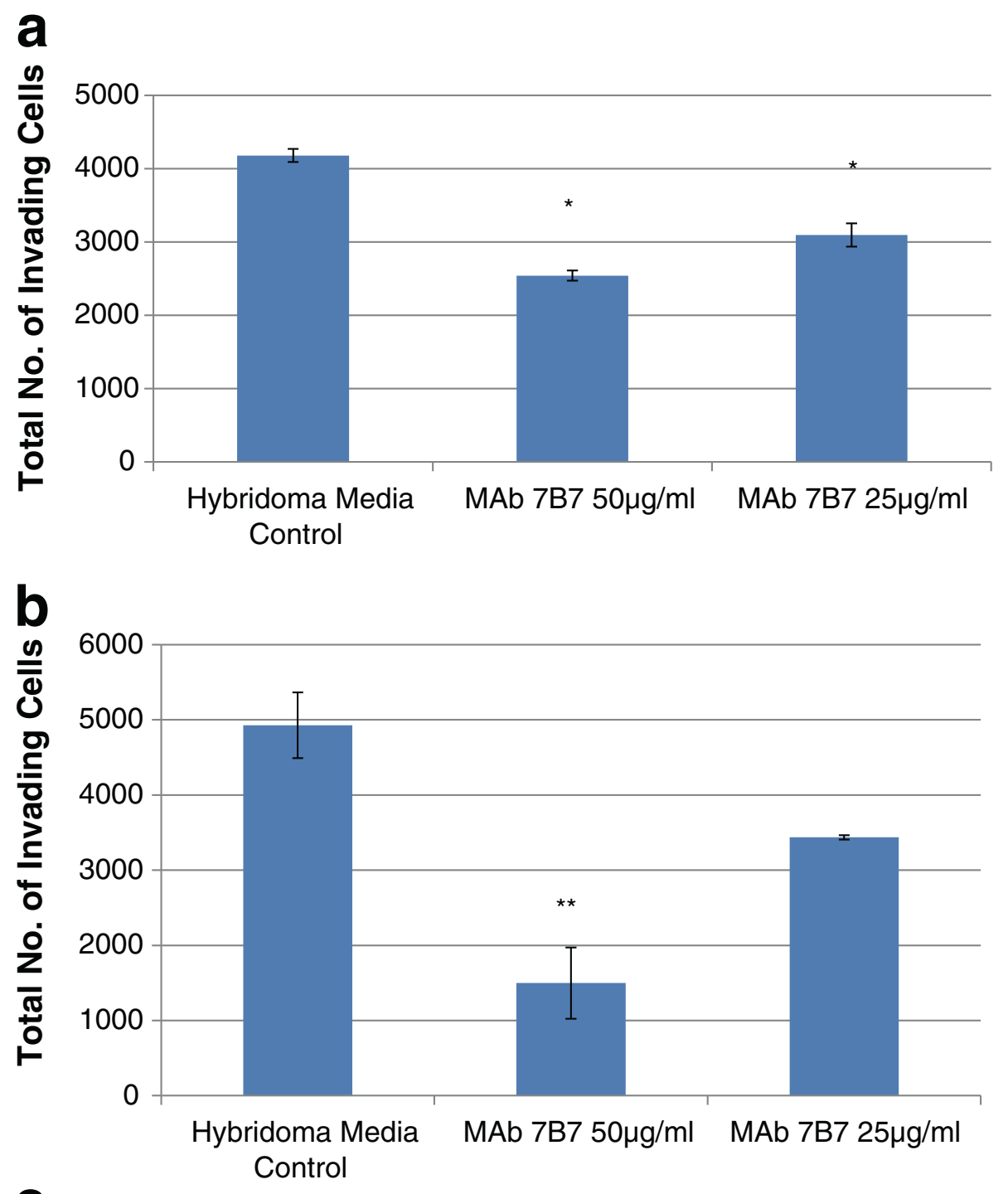

C

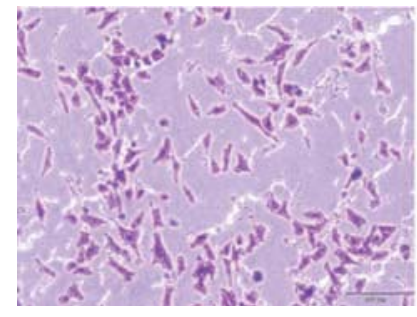

Hybridoma Medium Control

d

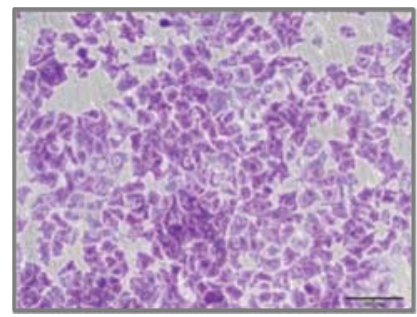

Hybridoma Medium Control

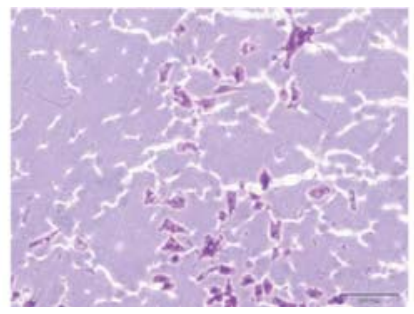

MAb 7B7 $50 \bullet \mathrm{g} / \mathrm{ml}$

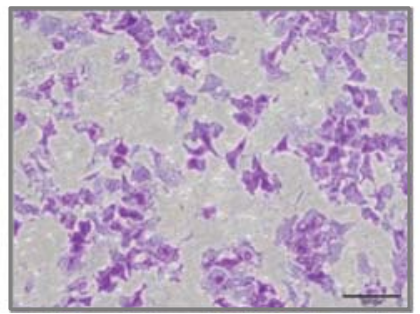

MAb 7B7 $50 \bullet \mathrm{g} / \mathrm{ml}$

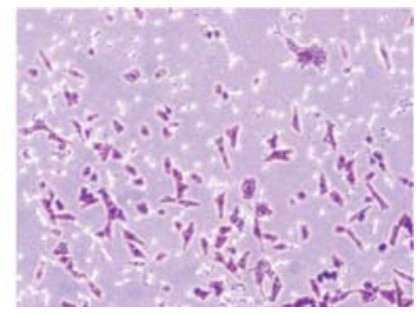

MAb 7B7 $25 \bullet \mathrm{g} / \mathrm{ml}$

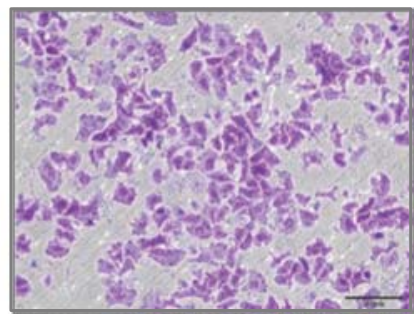

MAb 7B7 $25 \bullet \mathrm{g} / \mathrm{ml}$ 
4 Fig. 1 MAb 7B7 blocks cancer invasion in PDAC Mia PaCa-2 clone 3 cells and DLKP-M squamous lung cells. a The invasive potential of Mia $\mathrm{PaCa}-2$ clone 3 cells is significantly reduced in the presence of $50 \mu \mathrm{g} / \mathrm{ml}$ of antibody 7B7; invasion is also reduced, to a lesser extent, in the presence of $25 \mu \mathrm{g} / \mathrm{ml}$ of antibody, indicating that MAB $7 \mathrm{~B} 7 \mathrm{can}$ significantly reduce the invasive potential of this cell line in a doseresponsive manner. b The invasive potential of DLKP-M cells is significantly reduced in the presence of $50 \mu \mathrm{g} / \mathrm{ml}$ of antibody $7 \mathrm{~B} 7$; invasion is also reduced, to a lesser extent, in the presence of $25 \mu \mathrm{g} / \mathrm{ml}$ of antibody, indicating that MAB 7B7 can significantly reduce the invasive potential of this cell line in a dose-responsive manner. In both cases, the total number of cells invading through Matrigel is shown. Data plotted represent the mean \pm standard deviation from a representative experiment carried out in duplicate. Statistics: ${ }^{*} p \leq 0.05$, * ${ }^{*} p \leq 0.01$, and $* * * p \leq 0.005$ compared with hybridoma medium control (no MAb). Student's $t$ test (two-tailed with equal variance, unpaired). c Representative photomicrographs of Mia PaCa-2 clone cells invaded through Matrigel-coated Boyden invasion chambers $(8-\mu \mathrm{m}$ pore size) (stained with $0.25 \%$ crystal violet $(w / v)$ in the presence of two different concentrations of antibody (original magnification, $\times 100$; scale bar $=$ $200 \mu \mathrm{m})$. d Representative photomicrographs of DLKPM cells invaded through Matrigel-coated Boyden invasion chambers $(8-\mu \mathrm{m}$ pore size) (stained with $0.25 \%$ crystal violet $(w / v)$ in the presence of two different concentrations of antibody (original magnification, $\times 100$; scale bar $=$ $200 \mu \mathrm{m})$. All experiments were performed a minimum of three times, and representative results are presented

Hybridomas 7B7 and 6E2 were selected based on their ability to inhibit invasion. In parallel, hybridoma supernatants were screened for membrane fluorescence immunoreactivity using an FITC-labelled secondary antibody, on unfixed Mia PaCa- 2 clone 3 cells. Twenty-two supernatants (from a total of 335 screened) showed strong immunoreactivity on Mia Paca-2 clone 3 cells. Hybridomas 8F4, 3E2, 5B5, 1E5, 6D6 and 7B7 showed strong immunoreactivity; $8 \mathrm{~F} 4$ and 7B7 showed more intense staining in Mia PaCa-2 clone 3 cells compared with the poorly invasive $\mathrm{Mia} \mathrm{PaCa}-$ 2 clone 8 cells. Selected antibodies 7B7 and 6E2 were cloned by limiting dilution and re-screened (duplicate samples) using both the 24-well and the 96-well invasion assay methods. The $7 \mathrm{~B} 7$ clone G52 was selected for further study as it showed the strongest anti-invasive effects in Mia PaCa- 2 clone 3 cells and showed strong cell surface expression on these cells (Figs. 1 and 2) (note that 7B7 G52 is referred to, throughout this manuscript as $7 \mathrm{~B} 7$, its parental name).

\section{Isotyping of MAb 7B7}

Using a commercial isotyping kit, the isotype of antibody 7B7 was determined to be an $\operatorname{IgM}$ (data not shown).

MAb 7B7 impedes the invasive potential of aggressive cancer cells in vitro

In order to ascertain if antibody 7B7 could also impede invasion in other aggressive cancer cell types, we also investigated its anti-invasive effects in glioma, lung, colon and breast cancer cell lines. Antibody 7B7 blocked the ability of DLKP-M squamous lung carcinoma cells (mean inhibition level of $32.2 \%$ ) (Fig. 2) and H1229 large cell lung carcinoma cells (mean inhibition level of $30.6 \%$ ) to invade through Matrigel (Supplementary Fig. 5). The anti-invasive effects of $7 \mathrm{~B} 7$ in the other aggressive cancer types were not as marked: SNB-19 glioma, mean inhibition level of $27 \%$; HCT-116 colon adenocarcinoma, mean inhibition level of $24.2 \%$; SKBR-3 HER-2 positive breast, mean inhibition level of $25.6 \%$; and TNBC MDA-MB-231, mean inhibition level of $23 \%$ in the presence of identical concentrations of 7B7 (50 $\mu \mathrm{g} / \mathrm{ml})$ (Supplementary Figs. 5-9) (mean inhibition, figures from a minimum of three independent experiments). To further characterise the 7B7 functional blocking antibody, its
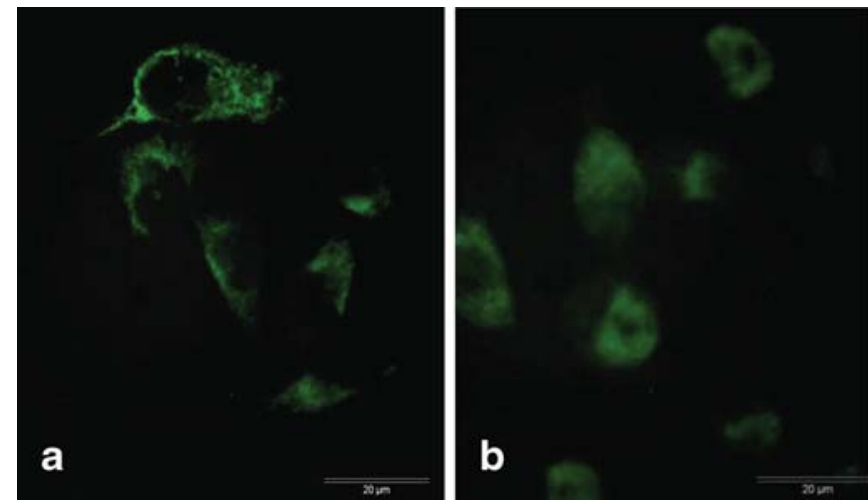

Fig. 2 Immunofluoresence cell surface staining of antibody 7B7. Mia $\mathrm{PaCa}-2$ clone 3 (a) and Mia PaCa-2 clone 8 (b) pancreatic ductal adenocarcinoma cells and DLKP Mitox-BCRP 6P, drug-resistant lung squamous carcinoma cells (H. Joyce, unpublished) (c) with their sensitive parent cells, DLKPSQ (d) and stained with antibody 7B7. Membrane 7B7 immunoreactivity is observed in invasive Mia PaCa-2 clone 3 and
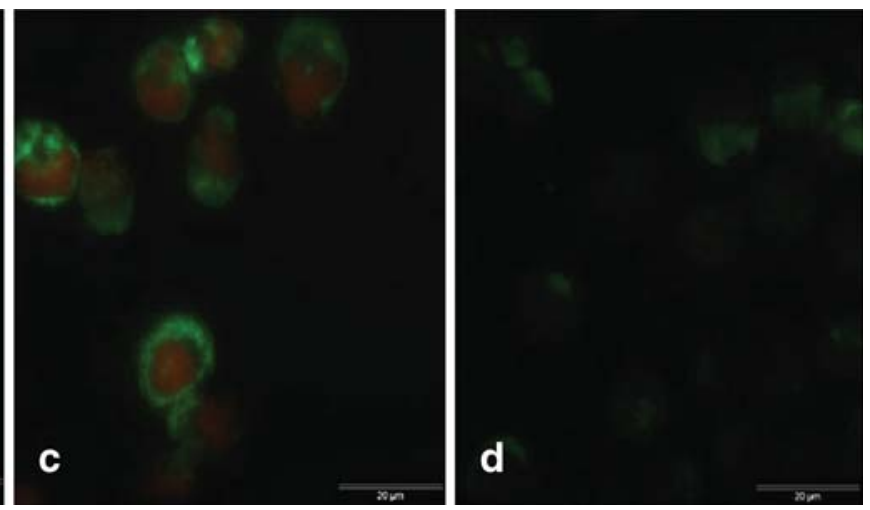

drug-resistant DLKP Mitox-BCRP 6P cells, Mia PaCa-2 clone 8 cells which are poorly invasive in vitro show more cytoplasmic-like 7B7 immunoreactivity only, DLKPSQ cells show very weak 7B7 immunoreactivity. c, d Counter stained with propidium iodide. Original magnification of all photomicrographs, $\times 400$, scale bar $=20 \mu \mathrm{m})$ 
ability to inhibit invasion in a dose-responsive manner was determined in Mia PaCa-2 clone 3 cells and DLKP-M squamous carcinoma cells (Fig. 1). Antibody 7B7 significantly inhibited invasion in a dose-responsive manner in both cell lines; representative histograms are presented in Fig. 1. Furthermore, 7B7 was also found to inhibit motility in a dose-responsive manner in $\mathrm{Mia} \mathrm{PaCa}-2$ clone 3 cells (Supplementary Fig. 3); effects on motility in other aggressive cell types were not determined, so it cannot be concluded if antibody 7B7 is capable of blocking cancer cell motility.

MAb 7B7 recognises a membrane-associated target antigen

Immunofluorescence staining of highly invasive Mia PaCa-2 clone 3 cells and drug-resistant Mitox6p cells with 7B7 revealed strong membrane reactivity on both of these cell lines (Fig. 2); weaker immunoreactivity was observed on poorly invasive Mia PaCa- 2 clone 8 cells and DLKP-SQ, the parental drug-sensitive clone of DLKPSQ Mitox-BCRP 6P. These results suggested that the $7 \mathrm{~B} 7$ antigen may possibly be associated with an aggressive cancer phenotype, i.e. highly invasive or drug-resistant cells relative to poorly invasive/drugsensitive cells. Taken together with $7 \mathrm{~B} 7 \mathrm{~s}$ ability to impede the invasive potential of various cancer cell types, the observed 7B7 immunoreactivity strongly suggests that this antibody binds to its native putative target antigen on the cell surface in these invasive cell lines.

\section{Identification of the 7B7 target antigen}

Sodium dodecyl sulphate polyacrylamide gel electrophoresis (SDS-PAGE) separation followed by Western blotting analysis with antibody $7 \mathrm{~B} 7$ revealed no potential reactive antigen band(s), suggesting that this antibody is recognising a conformational and not a linear epitope. We previously successfully used an immunoprecipitation approach coupled with proteomic analysis to identify the target antigen of antibody $5 \mathrm{C} 3$ [23]. As we had determined the isotype of antibody 7B7 to be an IgM, we used a modification of our previous approach utilising a commercially sourced immunoprecipitation kit which involved directed immobilisation of purified antibody to aldehyde-activated agarose beads. So in addition to eliminating immunoprecipitated contaminating antibody, protein $\mathrm{A} / \mathrm{G}$ is not involved, thus its suitability for IgM immobilisation. Cell extracts from Mia PaCa-2 clone 3 cells and DLKP$M$ cells were immunoprecipitated with MAb 7B7. SDSPAGE and MS-compatible Coomassie Blue staining revealed two reactive bands of approximately 80 and $70 \mathrm{kDa}$, in immunoprecipitates from both cell lines which were not present on control mouse IgM immunoprecipitates. A representative gel is shown in Fig. 3 showing reactive bands in immunoprecipitated $\mathrm{Mia} \mathrm{PaCa}-2$ clone 3 extracts. These two bands were excised and subjected to mass spectrometry

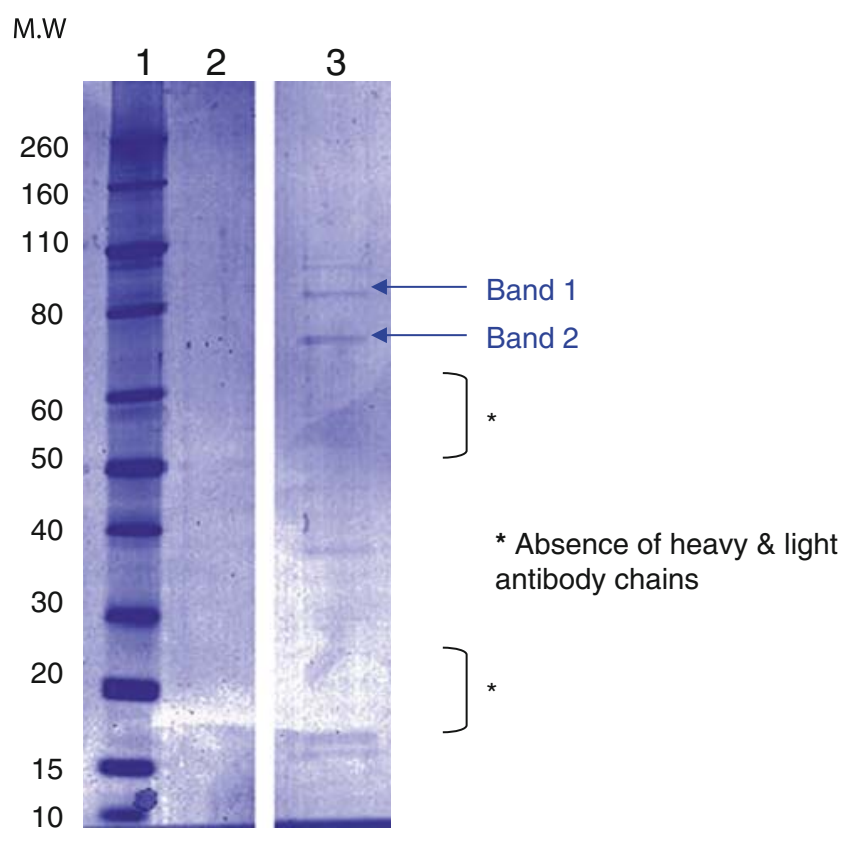

Fig. 3 Identification of MAb 7B7 target antigens by immunoprecipitation. Cross-linked immunoprecipitation of cell lysates with 7B7 MAb and control mouse IgM separated by SDS-PAGE and stained with $0.25 \%$ Coomassie Blue. Lane 1 molecular weight markers, lane $2 \mathrm{Mia} \mathrm{PaCa}-2$ clone 3 immunoprecipitated with mouse IgM, lane $3 \mathrm{Mia} \mathrm{PaCa}-2$ clone 3 immunoprecipitated with MAb 7B7. Two bands are observed; at approximately $80 \mathrm{kDa}, 70 \mathrm{kDa}$ was excised and run through an LCMS/LTQ mass spectrometer for identification. No antibody heavy and light chains are present. Non-binding agarose beads were also used as a control (data not shown). Experiment was performed three times, and a representative scanned gel is shown. DLKP-M cells were also immunoprecipitated with antibody $7 \mathrm{~B} 7$ and resulted in the same 70 and $80-\mathrm{kDa}$ reactive bands (data not shown)

identification using the SWISS-PROT database; the 70 and $80-\mathrm{kDa}$ bands were identified as the ATP-dependent DNA helicase 2 subunit 1 (Ku70) (molecular weight, 69.79 kDa) and the $80 \mathrm{kDa}$ ATP-dependent DNA helicase 2 subunit 2 (Ku80) (molecular weight, $82.65 \mathrm{kDa}$ ) (Table 1). Immunoprecipitates were validated with commercial antibodies directed against $\mathrm{Ku} 70$ and Ku80, confirming these identifications (Supplementary Fig. 18).

Table 1 The 7B7 target antigens identified by immunoprecipitation/LCMS-MS

\begin{tabular}{llll}
\hline Protein name & $\begin{array}{l}\text { Gene } \\
\text { symbol }\end{array}$ & $\begin{array}{l}\text { Protein AC } \\
\text { number }\end{array}$ & MW (kDa) \\
\hline $\begin{array}{c}\text { ATP-dependent DNA } \\
\text { helicase 2 subunit 1 }\end{array}$ & XRCC6 & gi|169145199| & 69.79 \\
$\begin{array}{c}\text { ATP-dependent DNA } \\
\text { helicase 2 subunit 2 }\end{array}$ & XRCC5 & gi|125731| & 82.65 \\
\hline
\end{tabular}

These proteomic identifications were validated by probing Mia $\mathrm{PaCa}-2$ clone 3 and DLKP-M immunoprecipitates with commercial antibodies specific for both the $\mathrm{Ku} 70$ and $\mathrm{Ku} 80$ subunits of the $\mathrm{Ku}$ heterodimer, confirming these proteomic identifications

$M W$ molecular weight 
RNA interference-mediated knockdown of $\mathrm{Ku} 70$ and $\mathrm{Ku} 80$ suppresses the invasive capacity of Mia PaCa-2 clone 3 and DLKP-M cells

As we had demonstrated that incubation with MAb 7B7 can significantly inhibit tumour invasion in a dose-responsive manner in the Mia PaCa-2 clone 3 and DLKP-M cell lines, we then determined the effects of siRNA-mediated knockdown on proliferation and invasion to establish if $\mathrm{Ku} 70 / \mathrm{Ku} 80$ is functionally involved and thus has therapeutic relevance in these two aggressive cancer types. Two independent siRNAs were used to successfully knockdown both subunits of the $\mathrm{Ku}$ heterodimer in the two cell lines. Down regulation of both $\mathrm{Ku} 70$ and Ku 80 significantly reduced the invasive capacity of both cell lines to invade compared with cells transfected with scrambled control siRNA as indicated by a marked decrease in the number of cells invading through matrigel (Figs. 4 and 5).
Cells transfected with $\mathrm{Ku} 70$ and $\mathrm{Ku} 80$ siRNA grew at a similar rate to scrambled control transfected cells indicating that down regulation of $\mathrm{Ku} 70 / \mathrm{Ku} 80$ has no effect on proliferation in these cell lines, indicating that the anti-invasive effects of antibody 7B7 are not secondary to the effects on cell growth (Supplementary Figs. 12 and 13). These siRNA knockdown experiments demonstrate that $\mathrm{Ku} 70$ and $\mathrm{Ku} 80$ are required for invasion of these aggressive PDAC and squamous lung carcinoma cell lines and thus are functionally involved in pancreatic and lung cancer invasion in vitro.

MAb 7B7 impedes the adhesion potential of Mia PaCa-2 clone 3 and DLKP-M cells

Adhesion of a tumourigenic cell to the basement membrane is a crucial stage in the invasion process. Thus, the effect of $\mathrm{MAb} 7 \mathrm{~B} 7$ on the adhesive potential of Mia $\mathrm{PaCa}-2$ clone 3 $\mathbf{a}$

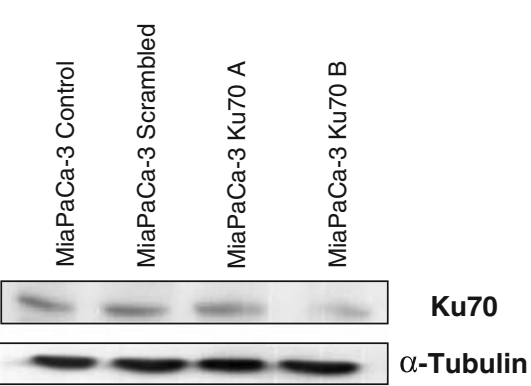

c

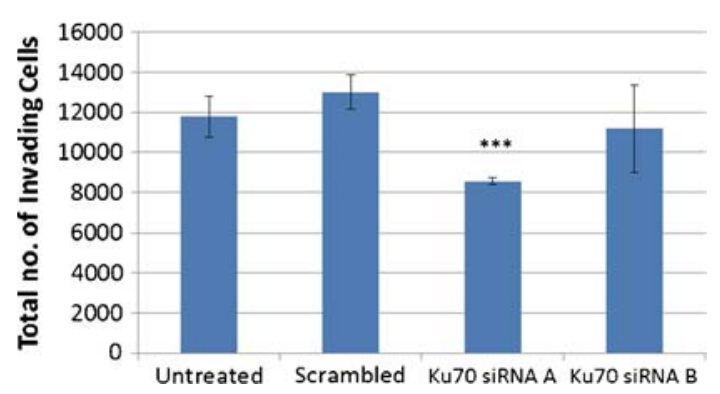

e

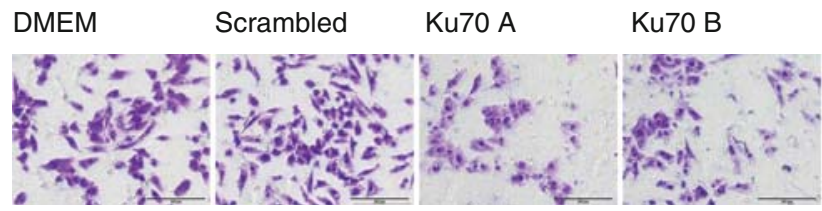

Fig. 4 The siRNA-mediated interference knockdown of both Ku70 and $\mathrm{Ku} 80$ reduces invasive capacity of $\mathrm{Mia} \mathrm{PaCa}-2$ clone 3 cells. a, b Immunoblots showing effective knockdown of $\mathrm{Ku} 70$ (a) and $\mathrm{Ku} 80$ (b) at 48 -h post-transfection in $\mathrm{Mia} \mathrm{PaCa}-2$ clone 3 cells transfected with two independent siRNAs targeting $\mathrm{Ku} 70$ and $\mathrm{Ku} 80$, respectively, relative to scrambled control siRNA-transfected cells. $\alpha$-Tubulin served as a loading control. c, $\mathbf{d}$ Representative histograms showing reduced invasive capacity of Mia PaCa- 2 clone 3 cells in a Boyden chamber assay following transfection with $\mathrm{Ku} 70$ - and $\mathrm{Ku} 80$-targeted siRNAs. The total number of cells invading through Matrigel is shown. Data plotted represent the mean b

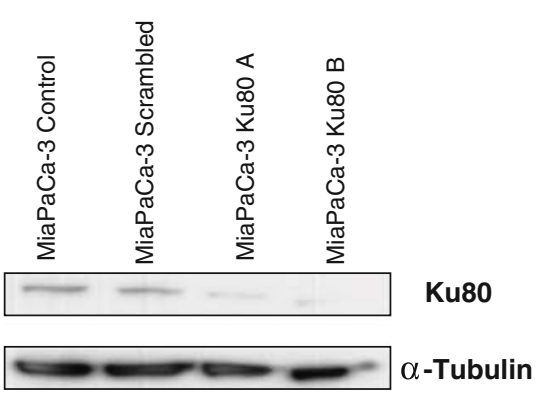

d

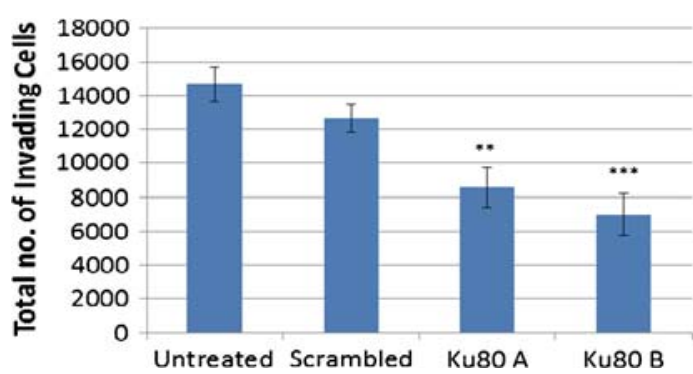

f

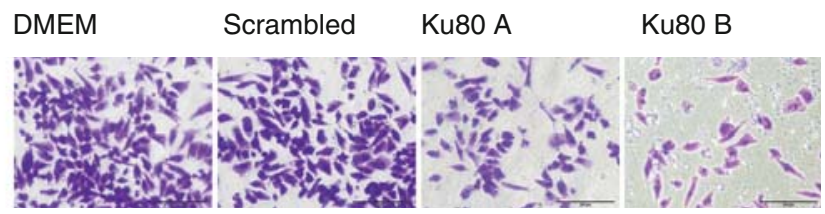

\pm standard deviation of duplicate transwell inserts from a representative experiment. Statistics: ${ }^{*} p \leq 0.05$, ${ }^{* *} p \leq 0.01$, and ${ }^{* * *} p \leq 0.005$ compared with scrambled siRNA control. Student's $t$ test (two-tailed with equal variance, unpaired). e, f Representative photomicrographs showing invasion status of Mia PaCa-2 clone 3 cells following transfection with siRNAs targeting $\mathrm{Ku} 70$ (e) and $\mathrm{Ku} 80$ (f), respectively. A decrease in invasion can be observed following siRNA transfections of both $\mathrm{Ku} 70$ and Ku80 compared with scrambled control insert. Original magnification, $\times 100$; scale bar $=200 \mu \mathrm{m}$. All experiments were performed in a minimum of three times, and representative results are presented 
$\mathbf{a}$

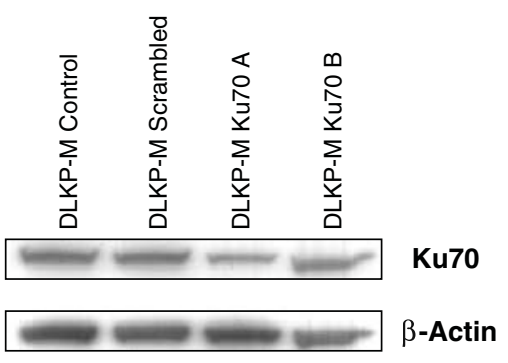

c

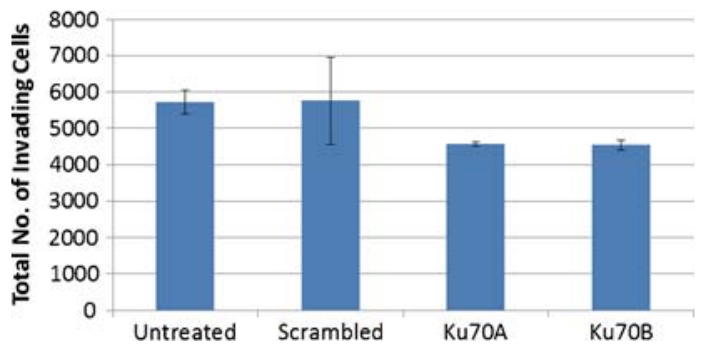

e

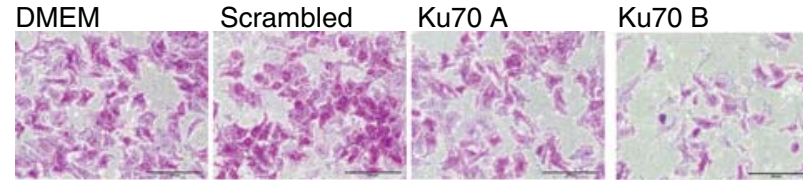

Fig. 5 siRNA-mediated interference knockdown of both $\mathrm{Ku} 70$ and Ku80 reduces invasive capacity of DLKP-M cells. a, b Immunoblots showing effective knockdown of $\mathrm{Ku} 70$ (a) and $\mathrm{Ku} 80$ (b) at 48-h posttransfection in DLKP-M cells transfected with two independent siRNAs targeting Ku70 and Ku80, respectively, relative to scramble control siRNA-transfected cells. $\alpha$-Tubulin served as a loading control. $\mathbf{c}, \mathbf{d}$ Representative histograms showing reduced invasive capacity of DLKP-M cells in a Boyden chamber assay following transfection with Ku70 and Ku80 siRNAs. The total number of cells invading through matrigel is shown. Data plotted represent the mean \pm standard deviation

cells was assessed. In the presence of MAb 7B7, a small decrease in the adhesion of Mia $\mathrm{PaCa}-2$ clone 3 cells to matrigel and DLKP-M cells to fibronectin was observed (Supplementary Figs. 10 and 11).

\section{MAb inhibits MMP activity in DLKPM cells}

Following treatment of squamous lung DLKP cells with antibody 7B7, effects on MMP activity were determined. As demonstrated in Fig. 6, zymographic analysis of conditioned medium (collected over $72 \mathrm{~h}$ ) from DLKP-M cells treated for $24 \mathrm{~h}$ with antibody 7B7 revealed reductions in pro and active MMP-10 and pro-MMP-2 compared with conditioned medium from cells treated with hybridoma control medium only. These results indicated that 7B7 may be eliciting its antiinvasive effects through reduction of MMP-2 and MMP-10 activities in DLKP-M cells. b

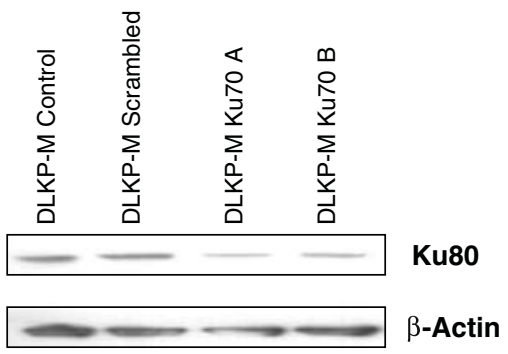

d

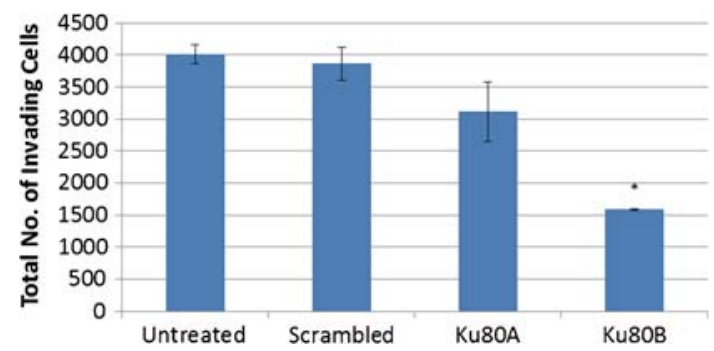

f

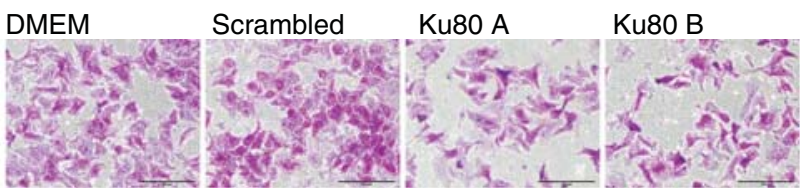

of duplicate transwell inserts from a representative experiment. Statistics: $* p \leq 0.05, * * p \leq 0.01$, and $* * * p \leq 0.005$ compared with scrambled siRNA control. Student's $t$ test (two-tailed with equal variance, unpaired). e, f Representative photomicrographs showing invasion status of DLKP-M cells following transfection siRNAs targeting Ku70 (e) and Ku80 (f), respectively. A decrease in invasion can be observed following siRNA transfection of both $\mathrm{Ku} 70$ and $\mathrm{Ku} 80$ compared with scrambled control insert. Original magnification, $\times 100$; scale bar $=200 \mu \mathrm{m}$ ). All experiments were performed in a minimum of three times, and representative results are presented

IHC analysis of $\mathrm{Ku} 70 / \mathrm{Ku} 80$ expression in pancreatic cancer

TMA cores were scored according to the intensity of the Ku70/Ku80 immunoreactivity observed (weak, moderate, and strong) (Table 2). Duplicate cores were stained in all cases; there was complete concordance between duplicates. Nuclear Ku70/Ku80 immunoreactivity was observed in all cases; some cytoplasmic localised staining was also observed. In addition, cytoplasmic staining of stromal cells was observed in a number of tumours. Ku70/Ku80 immunoreactivity was present in 40/40 tumours (37 PDAC, 2 acinar, and 1 squamous). All of the high-grade tumours studied exhibited either moderate or strong Ku70/Ku80 immunoreactivity, suggesting a possible trend of increased expression of $\mathrm{Ku} 70 / \mathrm{Ku} 80$ with more aggressive PDAC tumours. Weak $\mathrm{Ku} 70 / \mathrm{Ku} 80$ expression was also observed in $2 / 5$ normal pancreatic tissues; $3 / 5$ tissues showed intermediate immunoreactivity. Representative photomicrographs are shown in Fig. 7. 
We were not able to establish if membrane $\mathrm{Ku} 70 / \mathrm{Ku} 80$ expression is present in PDAC, as this commercial antibody has not been demonstrated to be specific for $\mathrm{Ku} 70 / \mathrm{Ku} 80 \mathrm{mem}$ brane expression.

\section{Discussion}

Despite the considerable success of MAbs in cancer therapy, there is still an unmet need for novel antibody therapeutics in oncology. Metastasis remains a huge therapeutic challenge, and a number of aggressive cancers currently lack welldefined therapeutic targets. The key challenge for antibody discovery for these unmet cancers is the continued identification of novel targets that are suitable for therapeutic antibody or ADC targeting. Therapeutic antibody target discovery can broadly be classified into two main approaches: antibody targeting of proteins with established, validated roles in cancer and antibody development without prior knowledge of the target which is based on functional screening.

Here, we report the isolation and characterisation of an antiinvasive blocking antibody which was identified using such a "functional screening" or function first hybridoma screening approach. Such phenotypic-based antibody screening approaches are increasingly been described for antibody discovery [24]. Our strategy involved the generation and selection of functional anti-invasive MAbs directed against the Mia PaCa-2 clone 3 cell line, with the overall objective of identifying cell surface protein targets with a direct role in cancer invasion that may be tractable to antibody/ADC therapy. This isogenic cell line which was previously isolated in this laboratory displays the characteristics of an aggressive cancer, with decreased adhesion facilitating increased invasion and motility coupled with an ability to survive in anchorage-independent conditions [19]. Furthermore, by immunising with cancer cells expressing functionally important antigens in their native cell surface configuration, it was more likely that we would isolate highly tumour-selective antibodies. Following fusion, hybridomas were screened based on their ability to inhibit invasion in their target cell line, Mia PaCa-2 clone 3 . In parallel, hybridoma supernatants were also screened by immunofluorescence staining on unfixed Mia PaCa- 2 clone 3 cells. Cell surface receptors are key targets for antibody-based therapeutics and account for over two thirds of current drug targets. The selected antibody 7B7 was chosen for further study, based on its ability to significantly impede invasion in Mia $\mathrm{PaCa}-2$ clone 3 cells and its strong membrane immunoreactivity in Mia PaCa-2 clone 3 cells with reduced staining in poorly invasive clone 8 cells. DLKP SQ Mitox6p cells, a drug-resistant clone also exhibited strong 7B7 immunoreactivity compared with its drug-sensitive parent (H. Joyce, unpublished). So, it appeared that the 7B7 target antigen may possibly be more highly expressed in cell lines that are representative of a more aggressive phenotype, i.e. highly invasive and/or chemoresistant.

We further demonstrated that antibody 7B7 could reduce cancer invasion in a panel of cell lines representing other aggressive tumour types (lung, glioma, colon, and breast). Its anti-invasive effects, however, were not as strong as that observed in Mia PaCa-2 clone 3. The observed variation in the extent of inhibition may reflect varying expression of the 7B7 target antigen in these cell lines, or it may suggest that our antibody is more selective for Mia $\mathrm{PaCa}-2$ clone 3 PDAC cells. As the most striking anti-invasive effects were observed in pancreatic and lung cell lines, we then demonstrated that $\mathrm{MAb} 7 \mathrm{~B} 7$ can significantly reduce invasion in a dosedependent manner in both Mia PaCa- 2 clone 3 and DLKP$M$ cells. Tumour invasion involves both the formation and the loss of adhesive contacts of tumour cells with the extracellular matrix. A small reduction in adhesion of Mia PaCa-2 clone 3 cells to ECM protein, fibronectin, and in adhesion of DLKP$\mathrm{M}$ cells to Matrigel in the presence of MAb 7B7 was also observed; this inhibitory effect on adhesion may be contributing to the significant decreases in the invasive potential observed in these aggressive cancer cells lines with MAb 7B7.

In addition to identifying a functional MAb with invasion-blocking activity, our study also aimed to reveal its target antigen. No signals could be detected when Western blotting was performed with antibody 7B7, suggesting that 7B7 is recognising a conformational and not a linear epitope. The anti-invasive effects of antibody 7B7 and cell surface immunoreactivity observed in invasive cancer cells indicate that this antibody is recognising a native target antigen on the membrane of these cells. Using an immunoprecipitation cross-lined method, mass spectrometry analysis using LC-MS-MS identified the immunoprecipitated 70 and $80 \mathrm{kDa}$ bands as the ATPdependent DNA helicase 2 subunit $1(\mathrm{Ku} 70)$ and the $80 \mathrm{kDa}$ ATP-dependent DNA helicase 2 subunit 2 (Ku80) (Table 1). The antibody immunoprecipitates were validated with commercial antibodies directed against the $\mathrm{Ku} 70$ and Ku80 subunits, confirming the proteomic identifications (Supplementary data). $\mathrm{Ku}$ is a heterodimeric protein composed of two subunits, $\mathrm{Ku} 70$ and $\mathrm{Ku} 80$; it was originally identified as an auto-antigen recognised by the sera of patients with autoimmune disease [25]. It is normally found in the nucleus where it plays a key role in non-homologous end joining (NHEJ), a major pathway in DSB repairs in humans [26]. Ku70/Ku80 is a key mediator in NHEJ and has been implicated in the radiosensitivity of a number of cancer types including the bladder, lung, breast, glioma, prostate, head and neck and cervix [27-34]. Ku has also been reported to be involved in cisplatin chemoresistance of some aggressive cancers such as lung adenocarcinoma, ovarian and leukaemic cells [30, 34]. 
Gelatin Zymography

a

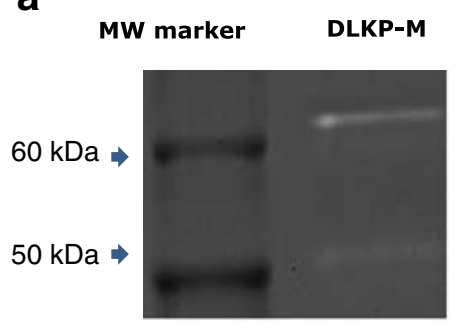

MMP-2

$62 \mathrm{kDa}$

MMP-10

$57 \mathrm{kDa}$

C

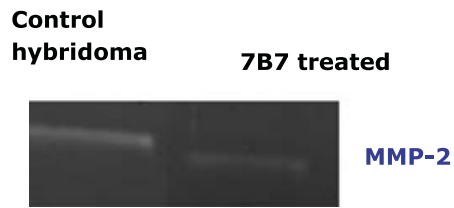

Fig. 6 Antibody 7B7 reduces MMP activity in squamous lung carcinoma DLKP-M cells. MMP activity in DLKP-M cells. a Gelatin zymography analysis of conditioned medium collected over $72 \mathrm{~h}$ from DLKP-M cells showing presence of both pro and active (lower band) MMP-2 in DLKP-M cells. b Caesin zymography analysis of conditioned medium collected over $72 \mathrm{~h}$ from DLKP-M cells showing the presence of both pro and active (lower band) MMP-10 in DLKP-M cells. MMP activity in DLKP-M cells treated with antibody 7B7. c Gelatin zymography analysis of conditioned medium collected over $72 \mathrm{~h}$

Functional antibody-blocking experiments with MAb 7B7 directed against $\mathrm{Ku} 70 / \mathrm{Ku} 80$ had demonstrated that incubation of Mia PaCa-2 clone 3 and DLKP-M cells with this antiinvasive antibody strongly suppressed invasion in a dosedependent manner in both cell lines. We then demonstrated

Table $2 \mathrm{Ku} 70 / \mathrm{Ku} 80$ immunoreactivity in grades 1,2 and 3 PDAC tumours

\begin{tabular}{ll}
\hline Grade 3 & $5 / 12$ strong \\
& $7 / 12$ moderate \\
Grade 2 & $3 / 12$ strong \\
& $5 / 12$ moderate \\
& $4 / 12$ weak \\
Grade 1 & $3 / 13$ strong \\
& $7 / 13$ moderate \\
& $3 / 13$ weak \\
\hline
\end{tabular}

Immunohistochemical analysis of $\mathrm{Ku} 70 / \mathrm{Ku} 80$ in $37 \mathrm{PDAC}$ tumours (duplicate cores), scores from histological grade 1 (low grade), grade 2 (intermediate) and grade 3 (high grade, more aggressive) PDAC tumours, is presented. The $\mathrm{Ku} 70 / \mathrm{Ku} 80$ (nuclear immunoreactivity) staining intensity was scored for each as weak, moderate or strong. Results presented represent the combined score of two cores from each tumour. High-grade tumours showed either moderate or strong immunoreactivity in all cases, suggesting a possible association of Ku70/Ku80 expression with a more aggressive PDAC phenotype. Representative photomicrographs are shown in Fig. 7
Caesin Zymography

b

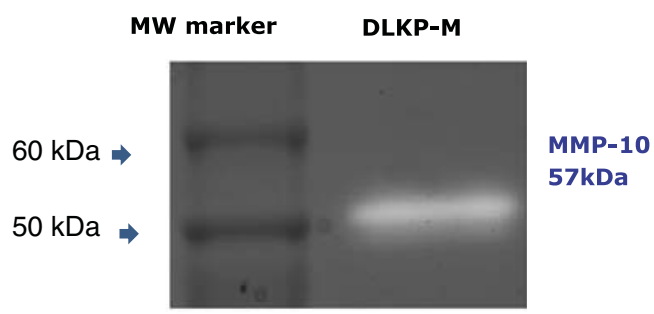

d

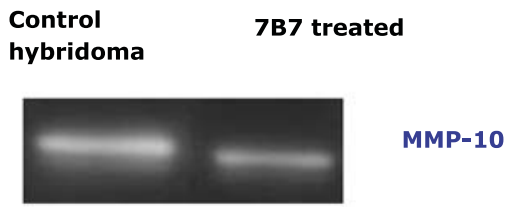

following treatment of DLKP-M cells with $50 \mu \mathrm{g}$ of MAb 7B7. A reduction in MMP-2 activity in DLKP-M antibody-treated cells is observed compared with control hybridoma medium only (no antibody). d Caesin zymography analysis of conditioned medium collected over $72 \mathrm{~h}$ following treatment with antibody 7B7. A marked reduction in MMP-10 activity (pro and active) is observed in DLKP-M cells treated with antibody 7B7 compared with cells treated with control hybridoma medium only (no antibody). Three independent experiments were performed in all cases, and representative zymograms are shown

that, for the first time, siRNA duplexes specific for both Ku70 and Ku80 could substantially reduce the invasive capacity of PDAC (Mia PaCa-2 clone 3) and lung squamous cancer cells (DLKP-M). These RNA interference-mediated knockdown results further strengthen our antibody-blocking results, indicating the functional involvement of Ku70/Ku80 in pancreatic and lung cancer invasion. The Ku heterodimer has been found to be expressed on the cell surface of various cancer cell lines (e.g. neuroblastoma, breast, cervix, and multiple myeloma) [26]. Ku 80 has been found to associate with latent and active MMP-9 on the cell surface of highly invasive haemapoietic cells [35]. MAb 7B7 showed strong membrane reactivity on invasive Mia $\mathrm{PaCa}-2$ clone 3 cells and on drug-resistant Mitox6p cells. Together with the anti-invasive effects of $\mathrm{MAb} 7 \mathrm{~B} 7$, these results strongly suggest that our antibody shows specificity for membrane-associated $\mathrm{Ku} 70 / \mathrm{Ku} 80$. A number of antibodies have been developed against $\mathrm{Ku} 70 / \mathrm{Ku} 80$; only one of these, the INCA-X antibody, has been demonstrated to show membrane-associated Ku70/Ku80 expression in human cancer tissue, glioma [36]. This group also demonstrated, using their antibody, that $\mathrm{Ku} 70 / \mathrm{Ku} 80$ is internalised into pancreatic carcinoma cells, suggesting that it has potential therapeutic value [37]. To our best knowledge, the involvement of Ku70/Ku80 in invasion of this aggressive cancer type or in lung cancer has not been studied to date. Studies on the role of Ku70/Ku80 in cancer invasion/ progression are limited. Inhibition of Ku80 with either 


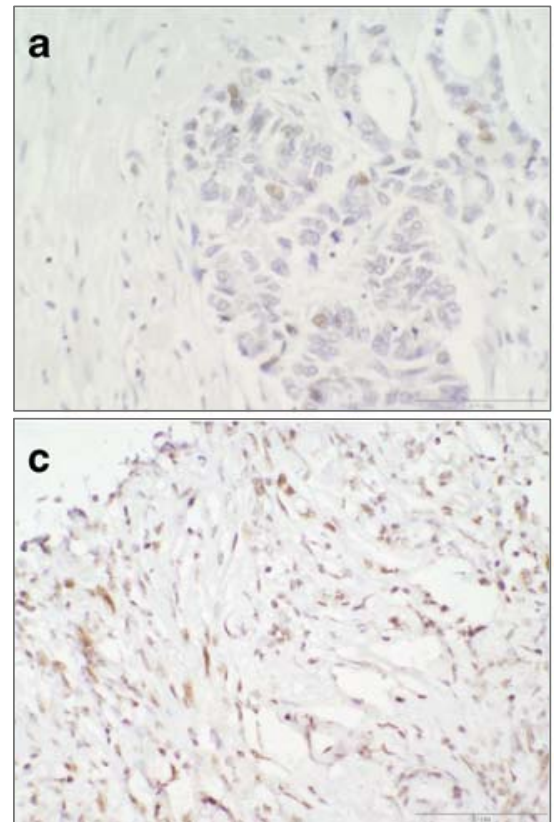

Fig. 7 Immunohistochemical analysis of $\mathrm{Ku} 70 / \mathrm{Ku} 80$ in (PDAC). $\mathrm{Ku} 70 / \mathrm{Ku} 80$ expression was studied in 37 PDAC tumours and 5 normal pancreatic tissues using a commercial pancreatic cancer TMA (US Biomax). Duplicate cores from each patient were stained, and $\mathrm{Ku} 70 / \mathrm{Ku} 80$ immunoreactivity was scored according to the staining intensity observed (weak, moderate, and strong; Table 2). Representative

neutralising antibodies or siRNA strongly reduced TRKmediated breast cancer invasion cancer [38].

To investigate how 7B7 may be exerting its anti-invasive effects, we then determined if antibody 7B7 could alter MMP activity. Treatment of DLKP-M cells with antibody 7B7 resulted in a reduction in both MMP-2 and MMP-10 activities. $\mathrm{Ku} 70 / \mathrm{Ku} 80$ has been shown to interact with MMP-9 in highly invasive cancer cells; to our knowledge, interactions with other MMPs have not been reported. So, antibody 7B7 may possibly be eliciting its anti-invasive effects by reducing MMP activity, at least in the cell line studied here.

It is likely that tumour progression is associated with enhanced NHEJ, and up regulation of $\mathrm{Ku} 70 / \mathrm{Ku} 80$ has been reported in a number of aggressive tumours such as lung adenocarcinoma, breast and gastric cancers [34, 39, 40]. Conversely, it has been suggested that deficient expression or lack of Ku70/Ku80 may result in genomic instability leading to tumourogenesis [41]. Earlier phases of melanoma progression are associated with loss of expression of $\mathrm{Ku} 70 / \mathrm{Ku} 80$, and the binding activity of $\mathrm{Ku} 70 / \mathrm{Ku} 80$ was reported to be strongly reduced at the advanced tumour stage in breast and bladder tumours [42, 43]. There are limited investigations focused on DNA repair proteins in pancreatic cancer. Ku70 has been implicated in the radiosensitivity of pancreatic carcinoma cells, has been shown to block Bax-mediated apoptosis and has been shown to be a secondary target for MDM2 inhibitor [44]. PDAC is highly refractory to systemic therapies

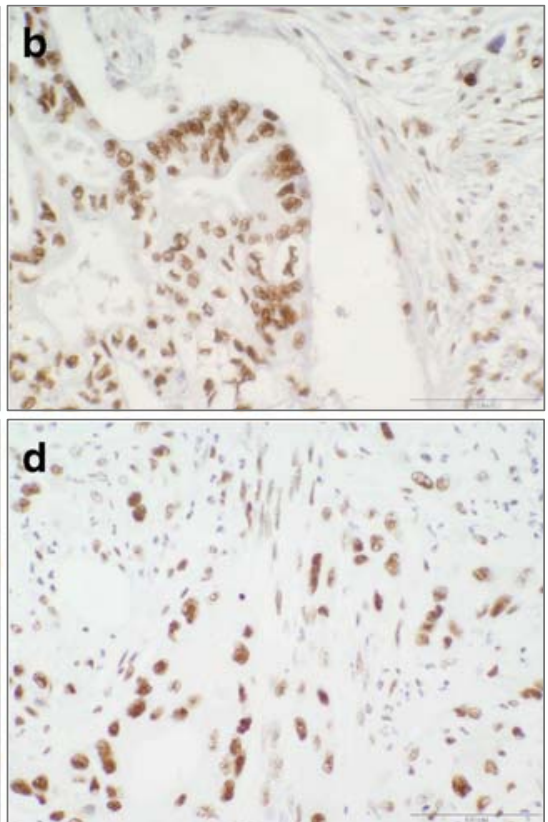

photomicrographs are shown, a a low-grade PDAC tumour showing weak Ku70/Ku80 immunoreactivity, while strong Ku70/Ku80-positive staining is observed in grade 2 (b) and grade 3 tumours (d). Stromal $\mathrm{Ku} 70 / \mathrm{Ku} 80$ immunoreactivity can be observed in $\mathbf{d}$ and in a second highgrade PDAC (c). Original magnification of photomicrographs of $\mathbf{a}, \mathbf{b}$ and $\mathbf{d}$ is $\times 400$ (scale bar $=100 \mu \mathrm{m} ; \mathbf{c} \times 200($ scale bar $=50 \mu \mathrm{m})$

and is characterised by a high propensity for local invasion and distant metastasis. There is an urgent need to develop new therapeutic strategies for this neoplasm. To ascertain if altered expression of $\mathrm{Ku} 70 / \mathrm{Ku} 80$ is involved in tumourogenesis in PDAC, we determined, using IHC, Ku70/Ku80 expression in 37 PDAC tumours and 6 normal pancreatic tissues. Our characterisation studies indicated that the 7B7 epitope was destroyed upon formalin fixation as we did not observe any immunoreactivity on archival tissues; therefore, a commercial $\mathrm{Ku} 70 / \mathrm{Ku} 80$ antibody was used for IHC studies. The $\mathrm{Ku}$ protein was expressed in all tumours studied, with a trend towards possible elevated expression of $\mathrm{Ku} 70 / \mathrm{Ku} 80$ in higher grade, i.e. more aggressive tumours. Ku70/Ku80 immunoreactivity was also observed in stromal cells in a number of tumours. We did observe Ku70/Ku80 expression in some of the normal pancreatic tissues stained, albeit weaker immunoreactivity than that observed in the majority of the tumours. Determination of $\mathrm{Ku} 70 / \mathrm{Ku} 80$ immunoreactivity (and tumour membrane specificity, if this can be demonstrated) in a larger PDAC patient cohort with follow-up will clarify the role of $\mathrm{Ku} 70 / \mathrm{Ku} 80$ in PDAC progression. In terms of its application as a potential antibody target for PDAC (or other aggressive neoplasms), immunohistochemical expression levels in an extended panel of normal tissues (including haemopoietic cells) will need to be carried out.

The preliminary IHC results presented here, however, demonstrate, for the first time, that $\mathrm{Ku} 70 / \mathrm{Ku} 80$ is widely 
expressed in PDAC. Taken together with invasion blocking and siRNA-mediated knockdown experiments, our study provides further evidence that targeting $\mathrm{Ku} 70 / \mathrm{Ku} 80$ with antibodies has therapeutic potential in pancreatic cancer. Our observed anti-invasive effects in other cancer cells, while not as striking as Mia PaCa-2 clone 3 and DLKP-M, suggest that $\mathrm{Ku} 70 / \mathrm{Ku} 80$ may be involved in the invasion of other aggressive cancer types; further, RNA-mediated interference knockdown studies would need to be carried out to confirm any potential functional role for $\mathrm{Ku} 70 / \mathrm{Ku} 80$ in these cancer types.

In summary, we have identified a cancer cell surface protein representing a potential therapeutic target through characterisation of an anti-invasive MAb generated using a functional hybridoma screening approach. Selection of MAbs based on their ability to inhibit cancer invasion and immunoprecipitation-based proteomic identification of putative target antigens has the potential to identify novel candidate membrane proteins for therapeutic antibody targeting or ADC targeting. Furthermore, our approach may also complement pre-defined target discovery approaches by assigning cancer-invasive-associated functions to known targets.

Acknowledgments This work was funded by Enterprise Ireland, project code TD/2009/0133. The authors wish to acknowledge the technical assistance provided by the RCSI Biomedical Facility, Beaumont Hospital, Dublin 9, Ireland.

\section{References}

1. Eckhardt BL, Francis PA, Parker BS, Anderson RL. Strategies for the discovery and development of therapies for metastatic breast cancer. Nat Rev Drug Disc. 2012;11:479-97.

2. Weber GF. Why does cancer therapy lack effective anti-metastasis drugs? Cancer Lett. 2013;328:207-11.

3. Scott AM, Allison JP, Wolchok JD. Monoclonal antibodies in cancer therapy. Cancer Immun. 2012;12:14.

4. Chames P, Van Regenmortel M, Weiss E, Baty D. Therapeutic antibodies: successes, limitations and hopes for the future. $\mathrm{Br} \mathrm{J}$ Pharmacol. 2009;157(2):220-33.

5. Lambert JM. Drug-conjugated antibodies for the treatment of cancer. Br J Clin Pharmacol. 2013;76(2):248-62. doi:10.1111/bcp.12044.

6. Reichert JM. Antibodies to watch in 2014. MAbs. 2013 Nov 25;6(1). [Epub ahead of print]

7. Scott AM, Wolchok JD, Old LJ. Antibody therapy of cancer. Nat Rev Cancer. 2012;12(4):278-87.

8. Sliwkowski MX, Mellman I. Antibody therapeutics in cancer. Science. 2013;341(6151):1192-8.

9. Mullard A. Maturing antibody-drug conjugate pipeline hits 30. Nat Rev Drug Discov. 2013;12(5):329-32.

10. Sievers EL, Senter PD. Antibody-drug conjugates in cancer therapy. Annu Rev Med. 2013;64:15-29.

11. Roti G, Stegmaier K. Genetic and proteomic approaches to identify cancer drug targets. Br J Cancer. 2012;106(2):254-61.

12. Swinney DC, Anthony J. How were new medicines discovered? Nat Rev Drug Discov. 2011;10(7):507-19.

13. Kohler G, Milstein C. Continuous cultures of fused cells secreting antibody of predefined specificity. Nature. 1975;256(5517):495-7.
14. Kinch MS, Kohli M, Goldblatt M, Li WB. Function-first approaches to improve target identification in cancer. Future Oncol. 2009;5(5): 617-23.

15. Frendeus B. Function-first antibody discovery: embracing the unpredictable biology of antibodies. Oncoimmunol. 2013;2(8): e25047.

16. Rust S, Guillard S, Sachsenmeier K, Hay C, Davidson M, Karlsson A, et al. Combining phenotypic and proteomic approaches to identify membrane targets in a 'triple negative' breast cancer cell type. Mol Cancer. 2013;12:11.

17. Walsh N, Dowling P, O'Donovan N, Henry M, Meleady P, Clynes M. Aldehyde dehydrogenase $1 \mathrm{~A} 1$ and gelsolin identified as novel invasion-modulating factors in conditioned medium of pancreatic cancer cells. J Proteomics. 2008;71(5):561-71.

18. McBride S, Meleady P, Baird A, Dinsdale D, Clynes M. Human lung carcinoma cell line DLKP contains 3 distinct subpopulations with different growth and attachment properties. Tumour Biol. 1998;19(2):88-103.

19. Walsh N, Clynes M, Crown J, O'Donovan N. Alterations in integrin expression modulates invasion of pancreatic cancer cells. J Exp Clin Cancer Res. 2009;28:140.

20. Albini A. Tumor and endothelial cell invasion of basement membranes. The matrigel chemoinvasion assay as a tool for dissecting molecular mechanisms. Pathol Oncol Res. 1998;4(3):230-41.

21. Martin A, Clynes M. Acid phosphatase: endpoint for in vitro toxicity tests. In Vitro Cell Dev Biol. 1991;27A(3 Pt 1):183-4.

22. Shevchenko A, Tomas H, Havlis J, Olsen JV, Mann M. In-gel digestion for mass spectrometric characterization of proteins and proteomes. Nat Protoc. 2006;1(6):2856-60.

23. Larkin A, Moran E, Kennedy SM, Clynes M. Monoclonal antibody $5 \mathrm{C} 3$ raised against formalin fixed paraffin-embedded invasive breast tumour tissue: characterisation of its reactive antigen via immunoprecipitation and internal sequencing. J Immunol Methods. 2005;303(1-2):53-65.

24. Beck A, Wurch T, Bailly C, Corvaia N. Strategies and challenges for the next generation of therapeutic antibodies. Nat Rev Immunol. 2010;10(5):345-52.

25. Tuteja N, Tuteja R, Ochem A, Taneja P, Huang NW, Simoncsits A, et al. Human DNA helicase II: a novel DNA unwinding enzyme identified as the Ku autoantigen. EMBO J. 1994;13(20):4991-5001.

26. Muller C, Paupert J, Monferran S, Salles B. The double life of the Ku protein: facing the DNA breaks and the extracellular environment. Cell Cycle. 2005;4(3):438-41.

27. Cosaceanu D, Budiu RA, Carapancea M, Castro J, Lewensohn R, Dricu A. Ionizing radiation activates IGF-1R triggering a cytoprotective signaling by interfering with $\mathrm{Ku}-\mathrm{DNA}$ binding and by modulating Ku 86 expression via a p38 kinase-dependent mechanism. Oncogene. 2007;26(17):2423-34.

28. Jia Q, Li Y, Xu D, Li Z, Zhang Z, Zhang Y, et al. Radiosensitivity of glioma to Gamma Knife treatment enhanced in vitro and in vivo by RNA interfering Ku70 that is mediated by a recombinant adenovirus. J Neurosurg. 2010;113(Suppl):228-35.

29. SoderlundLeifler K, Queseth S, Fornander T, Askmalm MS. Low expression of $\mathrm{Ku} 70 / 80$, but high expression of DNA-PKcs, predict good response to radiotherapy in early breast cancer. Int $\mathrm{J}$ Oncol. 2010;37(6):1547-54.

30. Hassan MK, Watari H, Christenson L, Bettuzzi S, Sakuragi N. Intracellular clusterin negatively regulates ovarian chemoresistance: compromised expression sensitizes ovarian cancer cells to paclitaxel. Tumour Biol. 2011;32(5):1031-47.

31. Petera J, Sirak I, Beranek M, Vosmik M, Drastikova M, Paulikova S, et al. Molecular predictive factors of outcome of radiotherapy in cervical cancer. Neoplasma. 2011;58(6):469-75.

32. Bouchaert P, Guerif S, Debiais C, Irani J, Fromont G. DNA-PKcs expression predicts response to radiotherapy in prostate cancer. Int $\mathrm{J}$ Radiat Oncol Biol Phys. 2012;84(5):1179-85. 
33. Groselj B, Kerr M, Kiltie AE. Radiosensitisation of bladder cancer cells by panobinostat is modulated by Ku80 expression. Radiother Oncol. 2013;108(3):429-33.

34. Ma Q, Li P, Xu M, Yin J, Su Z, Li W, et al. Ku80 is highly expressed in lung adenocarcinoma and promotes cisplatin resistance. J Exp Clin Cancer Res. 2012;31:99.

35. Monferran S, Paupert J, Dauvillier S, Salles B, Muller C. The membrane form of the DNA repair protein $\mathrm{Ku}$ interacts at the cell surface with metalloproteinase 9. EMBO J. 2004;23(19):3758-68.

36. Persson O, Salford LG, Fransson J, Widegren B, Borrebaeck CA, Holmqvist B. Distribution, cellular localization, and therapeutic potential of the tumor-associated antigen $\mathrm{Ku} 70 / 80$ in glioblastoma multiforme. J Neuro Oncol. 2010;97(2):207-15.

37. Fransson J, Borrebaeck CA. The nuclear DNA repair protein $\mathrm{Ku} 70 / 80$ is a tumor-associated antigen displaying rapid receptor mediated endocytosis. Int J Cancer. 2006;119(10):2492-6.

38. Lagadec C, Romon R, Tastet C, Meignan S, Com E, Page A, et al. Ku86 is important for TrkA overexpression-induced breast cancer cell invasion. Proteomics Clin Appl. 2010;4(6-7):580-90.

39. Alshareeda AT, Negm OH, Albarakati N, Green AR, Nolan C, Sultana R, et al. Clinicopathological significance of KU70/KU80, a key DNA damage repair protein in breast cancer. Breast Cancer Res Treat. 2013;139(2):301-10.

40. Li W, Xie C, Yang Z, Chen J, Lu NH. Abnormal DNA-PKes and Ku $70 / 80$ expression may promote malignant pathological processes in gastric carcinoma. World J Gastroenterol. 2013;19(40):6894-901.

41. Ferenczi K, Ohtola J, Aubert P, Kessler M, Sugiyama H, Somani AK, et al. Malignant T cells in cutaneous T-cell lymphoma lesions contain decreased levels of the antiapoptotic protein $\mathrm{Ku} 70$. Br J Dermatol. 2010;163(3):564-71

42. Pucci S, Mazzarelli P, Sesti F, Boothman DA, Spagnoli LG. Interleukin-6 affects cell death escaping mechanisms acting on Bax-Ku70-Clusterin interactions in human colon cancer progression. Cell Cycle. 2009;8(3):473-81.

43. Korabiowska M, Tscherny M, Stachura J, Berger H, Cordon-Cardo C, Brinck U. Differential expression of DNA nonhomologous endjoining proteins $\mathrm{Ku} 70$ and $\mathrm{Ku} 80$ in melanoma progression. Mod Pathol. 2002;15(4):426-33.

44. Azmi AS, Philip PA, Aboukameel A, Wang Z, Banerjee S, Zafar SF, et al. Reactivation of p53 by novel MDM2 inhibitors: implications for pancreatic cancer therapy. Curr Cancer Drug Targets. 2010;10(3):319-31. 